\title{
Glaucocalyxin A inhibits the growth of liver cancer Focus and SMMC-7721 cells
}

\author{
LISHA TANG ${ }^{*}$, XIAOFENG JIN* ${ }^{*}$ XIAOHUI HU, XIAODING HU, ZULONG LIU and LONG YU \\ School of Life Sciences, Fudan University, State Key Laboratory of Genetic Engineering, Shanghai 200433, P.R. China
}

Received January 23, 2015; Accepted October 21, 2015

DOI: $10.3892 / \mathrm{ol} .2015 .4002$

\begin{abstract}
Liver cancer is one of the most common types of cancer, and hepatoma demonstrates a poor long-term prognosis. The present study reports that glaucocalyxin A (GLA), a natural product isolated from Rabdosia umbrosa, inhibits the growth of the liver cancer Focus and SMMC-7721 cell lines in a dose- and time-dependent manner. The present study revealed that GLA arrested the liver cancer cells at the G2/M stage of the cell cycle and led to decreased expression of caspase 3 and the cleavage of poly(adenosine diphosphate-ribose) polymerase. Overall, the present study demonstrated that GLA inhibits the growth of liver cancer cells by G2/M stage cell-cycle arrest and cell apoptosis.
\end{abstract}

\section{Introduction}

Worldwide, liver cancer is the third most common cause of cancer-associated mortality (1). There are various approaches to the treatment of liver cancer, including chemotherapy, intervening therapy, liver transplantation and resection, which remains the most effective and the primary choice for the majority of patients (2). The prognosis for liver cancer patients following curative resection is improved compared to the prognosis without resection (3), and the 5-year survival rate increases between $<10 \%$ and $30-50 \%$ (4). Sorafenib, a mitogen-activated protein kinase inhibitor (5), is the most effective systemic chemotherapy agent for patients with advanced hepatocellular carcinoma (6). However, alternative treatment strategies for aggressive liver cancer are urgently required.

Natural compounds have been revealed to be beneficial when used alone or in combination with conventional therapies for the prevention of tumor progression or treatment of

Correspondence to: Professor Long Yu or Dr Xiaofeng Jin, School of Life Sciences, Fudan University, State Key Laboratory of Genetic Engineering, 220 Handan Road, Shanghai 200433, P.R. China

E-mail: longyu@fudan.edu.cn

E-mail: xiaofengjin12@fudan.edu.cn

${ }^{*}$ Contributed equally

Key words: liver cancer, growth inhibition, apoptosis, G2/M arrest human malignancies (7). Since the 1940 s, $48.6 \%$ of all cancer therapeutic agents approved by the US Food and Drug Administration and similar organizations are natural products or direct derivatives (8).

The Rabdosia genus is a rich source of diterpenoids, particularly ent-kaurene diterpenoids (9), which exhibit significant cytotoxicity and antitumor activities (10). Glaucocalyxin A (GLA; Fig. 1), also termed leukamenin F or $(5 \beta, 7 \alpha, 9 \beta, 10 \alpha)$-7,14-dihydroxykaur-16-ene-3,15-dione, is a chemical form of ent-kaurene diterpenoids that demonstrates a wide range of biological activities. GLA has been reported to attenuate lipopolysaccharide-stimulated neuroinflammation (11), inhibit protein kinase B phosphorylation in human-derived malignant glioma U87MG cells (12), cause a marked increase of platelet cyclic adenosine monophosphate levels (13), inhibit $\mathrm{H}_{2} \mathrm{O}_{2}$-induced $\mathrm{H} 9 \mathrm{c} 2$ cardiomyocyte injury (14), and induce apoptosis in a radical oxygen species-dependent mitochondrial dysfunction pathway (15). Furthermore, the intracellular glutathione-redox system is important in regulating the GLA-induced cytotoxicity on HL-60 cells (16).

In liver cancer, GLA has suppressed liver fibrogenensis, inhibited the proliferation of hepatic stellate cells (17) and has demonstrated cytotoxicity towards HepG2 cells (18), although the sensitivity of GLA to various types of liver cancer cells varied. The present study investigated the effect of GLA on liver cancer cells, revealing that GLA significantly inhibits the growth of the human liver cancer Focus and SMMC-772 cells.

\section{Materials and methods}

Chemicals and antibodies. GLA was isolated from the leaves of Rabdosia umbrosa according to previously published protocols (19). GLA was prepared as a $50 \mathrm{mmol} / 1$ stock solution in dimethyl sulfoxide (DMSO), and stored at $4{ }^{\circ} \mathrm{C}$. The purity of the stock solution was $>98 \%$. 5-fluorouracil (5-FU) was purchased from Sigma-Aldrich (St. Louis, MO, USA). The primary antibodies used in western blotting were: Monoclonal mouse anti-human $\beta$-actin monoclonal antibody (cat. no. A5316; 1:5,000; Sigma-Aldrich, St. Louis, MO, USA); polyclonal rabbit anti-human poly(adenosine diphosphate-ribose) polymerase (PARP) antibody (cat. no. 9542; 1:1,000; Cell Signaling Technology, Inc., Danvers, MA, USA); and polyclonal rabbit anti-human caspase 3 antibody (cat. no. 9662; 1:500; Cell Signaling Technology, Inc.). The secondary antibodies were 
horseradish peroxidase-conjugated anti-rabbit (cat. no. 7074; $1: 2,000$ ) and anti-mouse immunoglobulin G (cat. no. 7076; 1:5,000) (Cell Signaling Technology, Inc.).

Cell lines and cell culture. The human liver cancer SMMC-7721, epithelial HeLa, liver cancer SK-HEP1 and liver cancer HepG2 cell lines were obtained from American Type Culture Collection (Manassas, VA, USA). The human liver cancer Focus, pancreatic cancer PANC-1, leukemia K562, stomach cancer HGC-27, adenocarcinoma A549 and liver cancer QGY-7703 cell lines were purchased from the Chinese Academy of Sciences (Beijing, China). The SMMC-7721, HeLa, Focus and HepG2 cells were cultured in Dulbecco's Modified Eagle's medium (DMEM; Invitrogen; Thermo Fisher Scientific, Waltham, MA, USA) with $10 \%$ fetal bovine serum (FBS; Gibco; Thermo Fisher Scientific), while the K562, A549, SK-HEP1, QGY-7703, PANC-1 and HGC-27 cells were cultured in RPMI-1640 (Invitrogen; Thermo Fisher Scientific) with 10\% FBS. All cells were cultured at $37^{\circ} \mathrm{C}$ in a humidified incubator with $5 \% \mathrm{CO}_{2}$.

Cell viability assay. Cell viability was determined using a modified cell counting kit-8 (CCK-8) cellular proliferation assay (Dojindo Molecular Technologies, Inc., Kumamoto, Japan). Cells were plated in 96-well plates, and incubated with $0.00,3.13,6.25,12.50,25.00$ and $50.00 \mu \mathrm{mol} / 1$ GLA or 5 -FU for $48 \mathrm{~h}$. CCK-8 was administered for $2 \mathrm{~h}$, followed by absorbance measurement at $450 \mathrm{~nm}$ using a microplate reader (Model 550; Bio-Rad Laboratories, Inc., Hercules, CA, USA).

Sub-G1 analysis. Focus cells were plated in 6-well plates and incubated in DMEM with various concentrations of GLA for $24 \mathrm{~h}$. DMEM with $0.1 \%$ DMSO) was set as a control. The cells were harvested and washed in phosphate buffered saline (PBS) and resuspended in PBS containing $0.03 \%$ Triton X-100 (Santa Cruz Biotechnology, Inc., Dallas, TX, USA). The cells were then stained with a solution of $50 \mu \mathrm{g} / \mathrm{ml}$ propidium iodide (PI) for 15 min prior to analysis by flow cytometry (FCM; FACStar ${ }^{\mathrm{TM}}$ Plus; BD Biosciences, Franklin Lakes, NJ, USA). The sub-G1 cell subset was observed to reflect the percentage of apoptotic cells. The cycle distribution of cells was calculated by ModFit LT ${ }^{\mathrm{TM}}$ version 2.0 (Verity Software House, Inc., Toronto, ON, Canada).

Cell-cycle analysis. The Focus and SMMC-7721 cells were plated in 12-well plates and incubated in DMEM with various concentrations of GLA for $24 \mathrm{~h}$. DMEM with 0.1\% DMSO was set as a control. The cells were collected and washed in PBS and resuspended in PBS containing $0.03 \%$ Triton X-100 and $200 \mathrm{mg} / \mathrm{ml}$ RNase A (Sigma-Aldrich). The cells were stained in a solution of $50 \mu \mathrm{g} / \mathrm{ml}$ PI for $15 \mathrm{~min}$ prior to analysis by FCM (FACStar Plus). The cycle distribution of cells was calculated by ModFit LT.

Western blot analysis. The cells were lysed in ice-cold cell lysis buffer (Cell Signaling Technology, Inc.) containing $25 \mathrm{mmol} / \mathrm{l}$ Tris- $\mathrm{HCl}$ (pH 7.5), $150 \mathrm{mmol} / \mathrm{l} \mathrm{NaCl}, 1 \mathrm{mmol} / \mathrm{l}$ $\mathrm{Na}_{3} \mathrm{VO}_{4}, 1 \%$ Triton X-100 and protease cocktails. Equal amounts of lysates were resolved with 10\% SDS-PAGE and

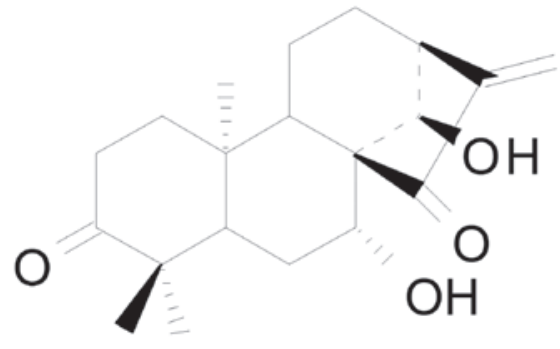

Figure 1. Structure of glaucocalyxin A.

transferred to a nitrocellulose membrane (GE Healthcare Life Sciences, Chalfont, UK). The membranes were stained with Ponceau S (Sigma-Aldrich) and probed with the $\beta$-actin antibody to confirm equivalent loading and protein transfer. Peroxidase-conjugated secondary antibodies were detected using enhanced chemiluminescence (GE Healthcare Life Sciences).

Statistical analysis. Data were expressed as the mean \pm standard deviation from $\geq 3$ sets of independent experiments. The Student's t-test was used to determine the significance of statistical differences. $\mathrm{P}<0.05$ was considered to indicate a statistically significant difference.

\section{Results}

GLA inhibits the growth of human cancer cells. A CCK-8 assay was used to investigate the cytotoxic activity of GLA on human cancer cells at various concentrations $(0.0,5.0$ and $50.0 \mu \mathrm{mol} / \mathrm{l})$ for $48 \mathrm{~h}$. GLA exhibited cytotoxicity against cancer cells from different tissues, including the PANC-1, K562, HGC-27, A549, SMMC-7721, HeLa, QGY-7703 and HepG2 cell lines (Fig. 2A).

To compare the effects of GLA with currently available chemotherapies, the same quantities of 5-FU and GLA were added into the DMSO medium used for SMMC-7721 cell culture. The synthesized chemotherapy drug 5-FU inhibits the growth of cancer cells by inhibiting thymidylate synthase, an enzyme which is essential for DNA synthesis (19). The administration of 3.13, 6.15, 12.25, 25.00 and $50.00 \mu \mathrm{mol} / 1$ GLA to SMMC-7721 cells led to cell viabilities of $0.752 \pm 0.015,0.756 \pm 0.015,0.250 \pm 0.025,0.112 \pm 0.08$ and $0.08 \pm 0.004 \mu \mathrm{mol} / 1$, respectively. The administration of the same concentrations of 5-FU to SMMC-7721 cells led to cell viabilities of $0.944 \pm 0.012,0.924 \pm 0.021,0.932 \pm 0.016$, $0.849 \pm 0.020$ and $0.714 \pm 0.024 \mu \mathrm{mol} / 1$, respectively. Therefore, GLA decreased the cell viability of SMMC-7721 cells more rapidly than 5-FU. The difference between the cell viabilities induced by GLA and 5-FU administration became more significant when the concentration of the agents was increased (Fig. 2B).

GLA inhibits the growth of liver cancer cells. For additional observation of the effect of GLA treatment, the liver cancer cells were plated in 96-well plates and incubated with DMEM and various concentrations of GLA $(0,0.62$, $1.85,5.56,16.67$ and $50.00 \mu \mathrm{mol} / \mathrm{l})$ for $48 \mathrm{~h}$. DMEM with the same volume of DMSO was set as a control. With 
A

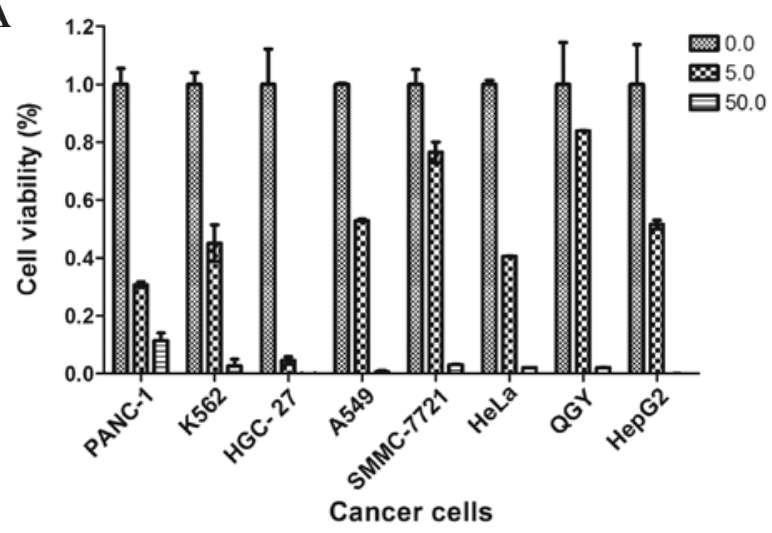

B

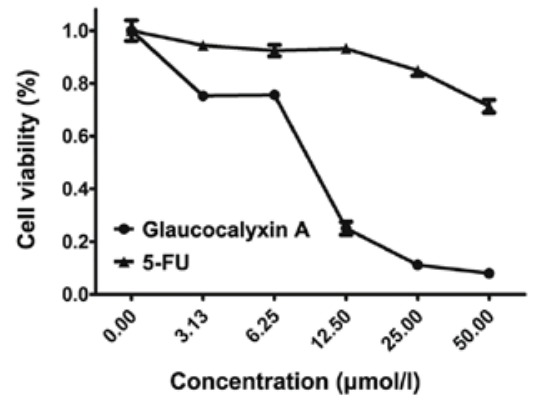

Figure 2. GLA inhibits the growth of cancer cells. Cancer cells were seeded in a 96-well plate and treated with various concentrations of GLA. Cell viability was measured by a cell counting kit- 8 assay, which was administered for $2 \mathrm{~h}$, following analysis using an absorbance measurement at 450 nm. (A) The PANC-1, K562, HGC-27, A549, SMMC-7721, HeLa, QGY-7703 and HepG2 cells were treated with 50.00 or $5.00 \mu$ mol/1 GLA for 48 h. (B) SMMC-7721 cells were treated with $0.00,3.13,6.25,12.50,25.00$ and $50.00 \mu \mathrm{mol} / 1 \mathrm{GLA}$ or 5 -FU for $48 \mathrm{~h}$. Cells incubated with $0.1 \%$ dimethyl sulfoxide were presented as $0.00 \mu \mathrm{mol} / 1$ and set as a control. The data are expressed as the mean \pm standard deviation of results from 3 independent experiments. GLA, glaucocalyxin A; 5-FU, fluorouracil.
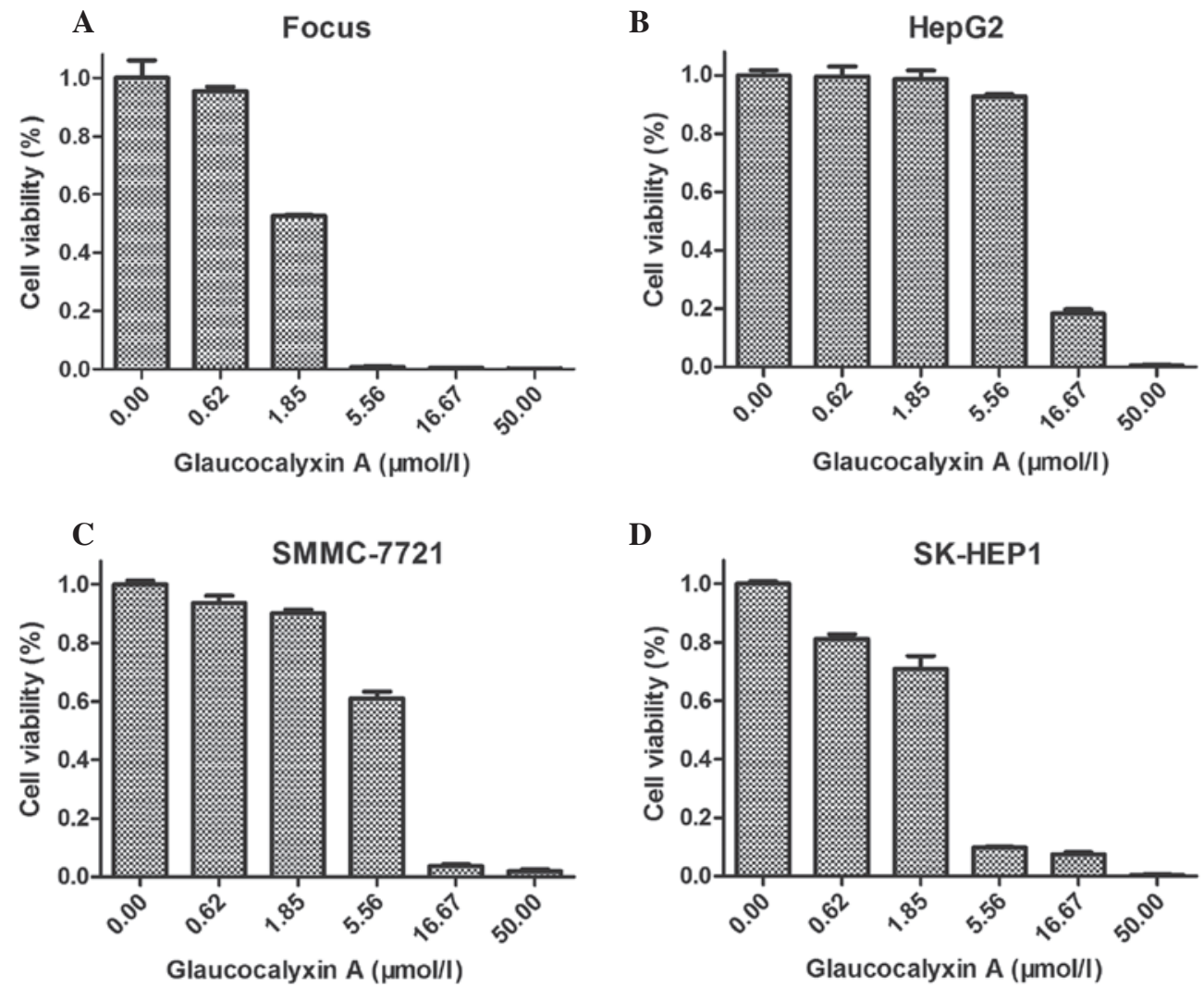

Figure 3. GLA inhibits the growth of liver cancer cells. (A) Focus, (B) HepG2, (C) SMMC-7721 and (D) SK-HEP1 cells were seeded in 96-well plates and treated with a series of concentrations of GLA $(0.62,1.85,5.56,16.67$ and $50.00 \mu \mathrm{mol} / \mathrm{l})$ for 48 h. Cell viability was measured by cell counting kit- 8 assay. Values are expressed as the mean \pm standard deviation from 3 independent experiments. GLA, glaucocalyxin A.

increased concentrations of GLA $(0,0.62,1.85,5.56,16.67$ and $50.00 \mu \mathrm{mol} / 1$ ), the liver cancer cells became round, floated and underwent cell death. The decrease of viable cell numbers with various concentrations of GLA is demonstrated in Fig. 3. The half maximal inhibitory concentration of GLA in Focus, SMMC-7721, HepG2 and SK-HEP1 cells was $2.70 \pm 0.09,5.58 \pm 0.20,8.22 \pm 0.56$ and $2.87 \pm 0.36 \mu \mathrm{mol} / 1$, respectively. Therefore, GLA inhibits the growth of liver cancer cells, particularly Focus and SK-HEP1 cells.
GLA induces apoptosis in liver cancer cells. Inhibition of proliferation and induction of apoptosis in cancer cells are each effective methods to clear tumors. To investigate whether the cell death of liver cancer cells induced by GLA was due to apoptosis, the present study analyzed Focus cells treated with GLA by FCM. The sub-G1 cell subset was observed to reflect the percentage of apoptotic cells. Focus cells incubated with GLA demonstrated a significant trend of dose-dependent apoptosis (Fig. 4A). When the cells were incubated with 

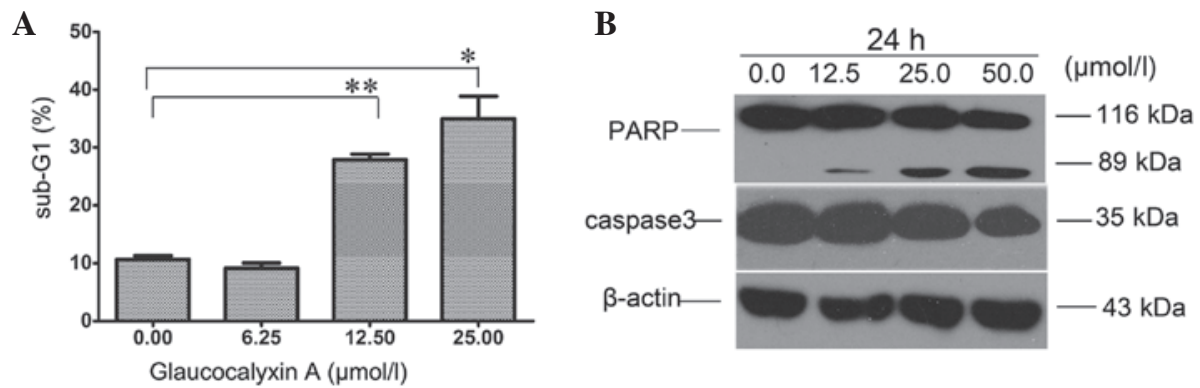

Figure 4. GLA induces liver cancer cells to undergo apoptosis. Focus cells were incubated with increasing concentrations of GLA (0.00, $6.25,12.5$ and $25.00 \mu \mathrm{mol} / 1$ ) for $48 \mathrm{~h}$ and harvested for FCM or western blot analysis. (A) Percentages of sub-G1 cells were examined by FCM. Values are expressed as the mean \pm standard deviation. The experiment was performed in triplicate. ${ }^{*} 0.01<\mathrm{P}<0.05 ;{ }^{* *} \mathrm{P}<0.01$. (B) Western blot analysis for the expression of $\mathrm{PARP}$ and caspase 3. GLA, glaucocalyxin A; FCM, flow cytometry; PARP, poly(adenosine diphosphate-ribose) polymerase.

A

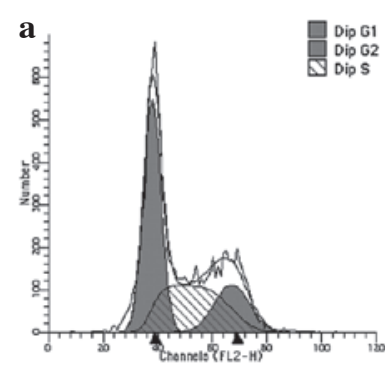

C
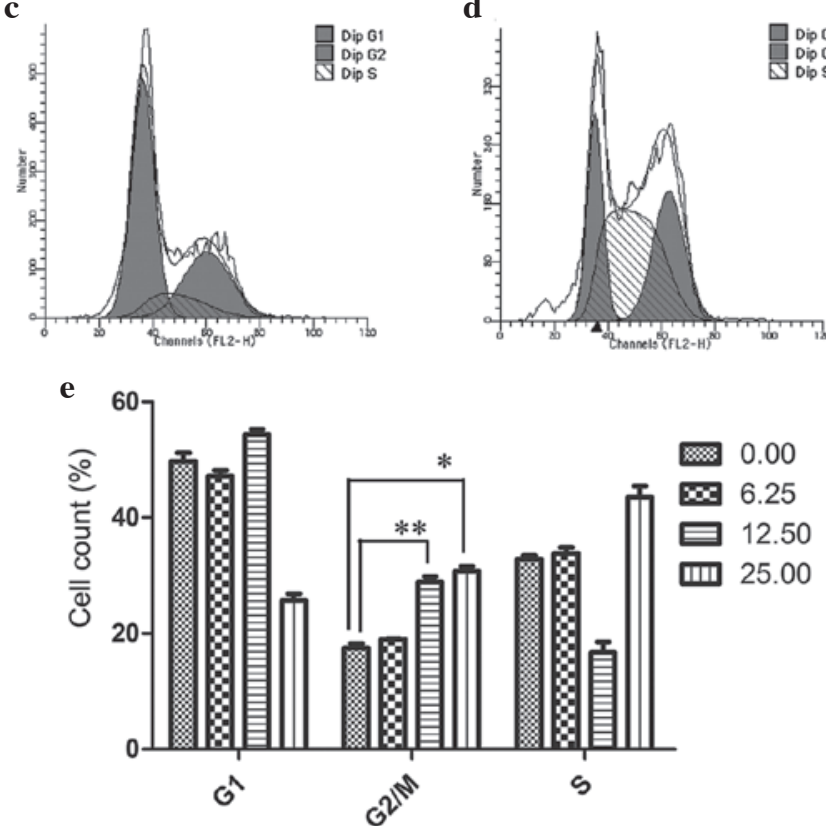

B

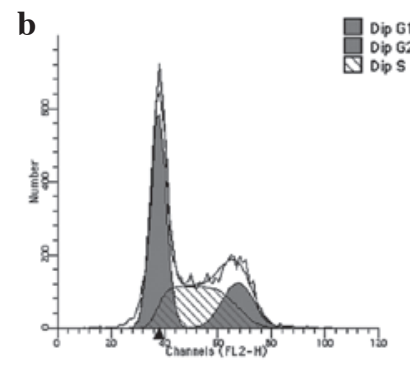

d

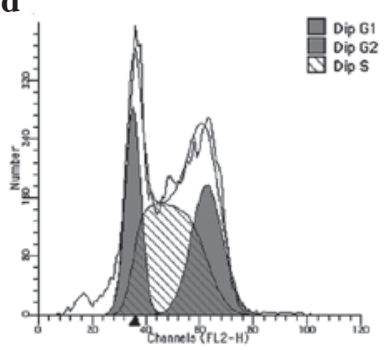

C b
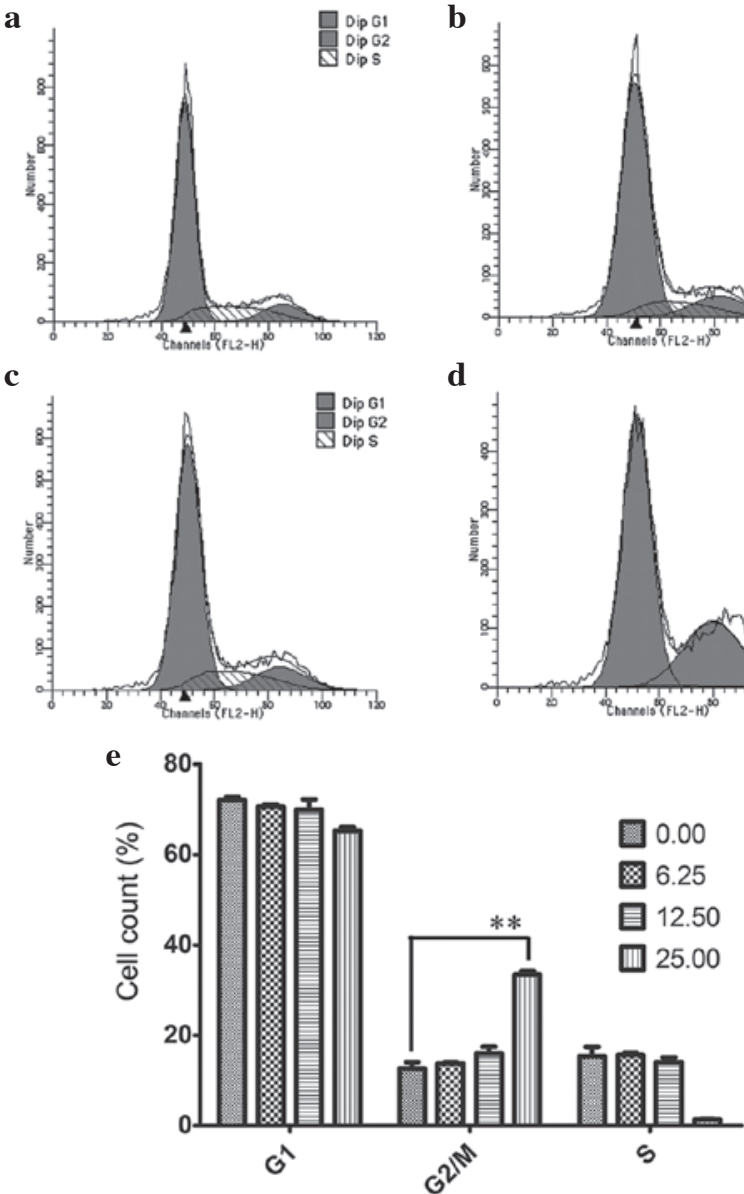

Figure 5. GLA leads to G2/M phase arrest of the cell cycle in liver cancer cells. The liver cancer Focus and SMMC-771 cell lines were incubated with GLA for $24 \mathrm{~h}$ prior to collection to examine the cycle distribution by flow cytometry. (A) Focus cells: (a) $0.1 \%$ DMSO; (b) $6.25 \mu$ mol/1 GLA; (c) $12.50 \mu$ mol/1 GLA; and (d) $25.00 \mu \mathrm{mol} / 1$ GLA. The results are representative of 3 independent experiments. (e) Cell counts of cycle distribution of Focus cells treated with GLA for 24 h. (B) SMMC-7721 cells: (a) $0.1 \%$ DMSO; (b) $6.25 \mu \mathrm{mol} / 1$ GLA; (c) $12.50 \mu \mathrm{mol} / 1$; and (d) $25.00 \mu \mathrm{mol} / 1$. (e) Cell counts of cycle distribution of SMMC-7721 cells treated with GLA for 24 h. $0.1 \%$ DMSO, presented as $0.00 \mu \mathrm{mol} / 1$, was set as a control. Values are expressed as the mean \pm standard deviation. ${ }^{*} 0.01<\mathrm{P}<0.05 ;{ }^{* *} \mathrm{P}<0.01$. GLA, glaucocalyxin A; DMSO, dimethyl sulfoxide.

GLA for $48 \mathrm{~h}$, the apoptotic rate increased slowly when the GLA concentration was $<6.25 \mu \mathrm{mol} / 1$, and then rose rapidly when the concentration increased to $12.50 \mu \mathrm{mol} / \mathrm{l}$. Western blotting revealed that cleaved-PARP was observed when the cells were treated with $12.50 \mu \mathrm{mol} / 1$ of GLA. There was a decrease in the expression of caspase 3 and full length PARP (116 kDa), and a dose-dependent increase in cleaved PARP
(89 kDa) (Fig. 4B). These findings indicate that GLA treatment leads to the apoptosis of liver cancer cells.

GLA induced G2/M arrest in liver cancer cells. The effect of GLA on cell cycle progression in Focus and SMMC-7721 cells was determined following $24 \mathrm{~h}$ of GLA treatment $(0.00,6.25$, 12.50 and $25.00 \mu \mathrm{mol} / \mathrm{l})$ using FCM. As indicated in Fig. 5A, 
there was a significant increase in the proportion of Focus cells in the G2/M phase when the concentration of GLA was $>12.50 \mu \mathrm{mol} / 1$. The alteration of cell cycle distribution in SMMC-7721 cells was similar to that in Focus cells, but the increase of the proportion of SMMC-7721 cells in the G2/M phase was not significant until the cells were treated with $25.00 \mu \mathrm{mol} / 1$ GLA (Fig. 5B).

\section{Discussion}

GLA is isolated from the leaves of R. umbrosa, which has been used in Asia for centuries as a medicinal herb for diminishing inflammation, invigorating the circulation of blood and relieving swelling and pain $(20,21)$. Consequently, verifying the effect that GLA has against liver cancer cells would be valuable. GLA is a natural form of ent-kaurene diterpenoids. Ent-kaurene diterpenoids isolated from the same Isodon plants were selectively toxic against tumor cell lines (22). The present study confirmed that GLA is toxic to SMMC-7721 cells (Fig. 3), which supported the results of a previous study (23). In addition, the present study demonstrated that GLA is also toxic to various cancer cells; however, the sensitivity to GLA varied between the cancer types. This may be due to GLA being involved in various gene expression pathways, which vary between cancer cells. For the same reason, certain liver cancer cells are more sensitive to GLA, including the Focus and SK-HEP1 cells.

Kaurene diterpenes exhibit toxicity against tumor cells through various methods. The ent-kaurene diterpenoid ent-16 $\beta$-17 $\alpha$-dihydroxykaurane triggered apoptosis of MCF-7 cells by a decrease in telomerase mRNA (24). Oridonin, ponicidin, xindongnin $\mathrm{A}$ and xindoninin have been demonstrated to be potent inhibitors of $\mathrm{NF}-\kappa \mathrm{B}$ transcription activity (25). To investigate the possible mechanism for the anti-proliferative ability of GLA, the present study examined the DNA content of liver cancer cells by FCM. Apoptotic cells were identified by the appearance of a sub-G1 peak. Focus cells treated with GLA demonstrated a significant increase in the sub-G1 fraction (Fig. 4A), which indicated that GLA induced apoptosis in liver cancer cells.

One of the major apoptosis pathways involves the release of cytochrome $c$ from mitochondria into the cytosol of cells. Cytosolic cytochrome $c$ induces caspase 9-dependent activation of caspase 3 and cleavage of the DNA repair protein PARP (26). As shown in Fig. 4B, the expression of caspase 3 and full-length PARP was decreased in GLA-treated cells, while the expression of cleaved PARP increased in a dose-dependent manner. Together, the slight alteration of caspase 3 expression and significant alteration of the sub-G1 fraction suggest that GLA may affect the mitochondrial pathway, including the caspase cascade, to induce apoptosis in Focus cells.

Cell cycle arrest is also an effective method of inhibiting the proliferation of cells. The deregulation of the cell cycle is one of the most frequent alterations observed during tumor development (27), and a cell cycle blockade is regarded as an effective strategy for eliminating cancer cells (28). The G1/S and G2/M checkpoints are two major regulated cell cycle checkpoints. The present study analyzed the cell cycle progression in Focus and SMMC-7721 cells treated with GLA for $24 \mathrm{~h}$. The results indicate a significant G2/M stage arrest in Focus and SMMC-7721 cells in a GLA dose-dependent manner (Fig. 5). This indicates that GLA induces G2/M arrest and therefore apoptosis of Focus and SMMC-7721 cells.

In summary, the present study, to the best of our knowledge, is the first to demonstrate that GLA has an inhibitory effect on the growth of Focus and SMMC-7721 cells. This may be due to G2/M cell cycle arrest and apoptosis being induced in cancer cells, although the target molecule of the GLA remains unknown.

\section{Acknowledgements}

This present study was supported by the National Key Sci-Tech Special Project of China (grant no. 2013ZX10002010).

\section{References}

1. Ferlay J, Shin HR, Bray F, Forman D, Mathers C and Parkin DM: Estimates of worldwide burden of cancer in 2008: GLOBOCAN 2008. Int J Cancer 127: 2893-2917, 2010.

2. Zhong JH, Li H, Xiao N, Ye XP, Ke Y, Wang YY, Ma L, Chen J, You XM, Zhang ZY, et al: Hepatic resection is safe and effective for patients with hepatocellular carcinoma and portal hypertension. PloS One 9: e108755, 2014.

3. Rahbari NN, Ulrich AB, Bruckner T, Münter M, Nickles A, Contin P, Löffler T, Reissfelder C, Koch M, Büchler MW and Weitz J: Surgery for locally recurrent rectal cancer in the era of total mesorectal excision: Is there still a chance for cure? Ann Surg 253: 522-533, 2011.

4. Takayama T: Surgical treatment for hepatocellular carcinoma. Jpn J Clin Oncol 41: 447-454, 2011.

5. Nagai T, Arao T, Furuta K, et al: Sorafenib inhibits the hepatocyte growth factor-mediated epithelial mesenchymal transition in hepatocellular carcinoma. Mol Cancer Ther 10: 169-177, 2011.

6. Llovet JM, Ricci S, Mazzaferro V, Hilgard P, Gane E, Blanc JF, de Oliveira AC, Santoro A, Raoul JL, Forner A, et al; SHARP Investigators Study Group: Sorafenib in advanced hepatocellular carcinoma. N Engl J Med 359: 378-390, 2008.

7. Usami Y, Takaoka I, Ichikawa H, Horibe Y, Tomiyama S, Ohtsuka M, Imanishi Y and Arimoto M: First total synthesis of antitumor natural product (+)- and (-)-pericosine A: Determination of absolute stereo structure. J Org Chem 72: 6127-6134, 2007.

8. Newman DJ and Cragg GM: Natural products as sources of new drugs over the 30 years from 1981 to 2010. J Nat Prod 75: 311-335, 2012.

9. Satooka H, Isobe T, Nitoda T and Kubo I: Melanogenesis inhibitors from Rabdosia japonica. Phytomedicine 19: 1016-1023, 2012.

10. Sun HD, Huang SX and Han QB: Diterpenoids from Isodon species and their biological activities. Nat Prod Rep 23: 673-698, 2006.

11. Kim BW, Koppula S, Hong SS, Jeon SB, Kwon JH, Hwang BY, Park EJ and Choi DK: Regulation of microglia activity by glaucocalyxin-A: Attenuation of lipopolysaccharide-stimulated neuroinflammation through NF- $\mathrm{KB}$ and p38 MAPK signaling pathways. PloS One 8: e55792, 2013.

12. Xiao X, Cao W, Jiang X, Zhang W, Zhang Y, Liu B, Cheng J, Huang H, Huo J and Zhang X: Glaucocalyxin A, a negative Akt regulator, specifically induces apoptosis in human brain glioblastoma U87MG cells. Acta Biochim Biophys Sin (Shanghai) 45: 946-952, 2013.

13. Zhang B and Long K: Effects of glaucocalyxin A on aggregation and cAMP levels of rabbit platelets in vitro. Zhongguo Yao Li Xue Bao 14: 347-350, 1993.

14. Liu MJ, Sun Q, Yu LJ, Bao GL and Zhao M: Protective effect of glaucocalyxin A inhibits $\mathrm{H}_{2} \mathrm{O}_{2}$-induced $\mathrm{H} 9 \mathrm{c} 2$ cardiomyocytes injury. Latin American J Pharmacy 33: 1216-1220, 2014.

15. Gao LW, Zhang J, Yang WH, Wang B and Wang JW: Glaucocalyxin A induces apoptosis in human leukemia HL-60 cells through mitochondria-mediated death pathway. Toxicol In Vitro 25: 51-63, 2011.

16. Yang WH, Zhang Z, Sima YH, Zhang J and Wang JW: Glaucocalyxin A and B-induced cell death is related to GSH perturbation in human leukemia HL-60 cells. Anticancer Agents Med Chem 13: 1280-1290, 2013. 
17. Liu Q, Wang X, Zhang Y, Li CJ,Hu LH and Shen X: Leukamenin F suppresses liver fibrogenesis by inhibiting both hepatic stellate cell proliferation and extracellular matrix production. Acta Pharmacol Sin 31: 839-848, 2010.

18. Ying N, Xu CL, Zhang J, Fu Q and Ma SP: The effects of glaucocalyxin A in hepatic cancer HepG2 cell line. Strait Pharm J 24: 235-238, 2012.

19. Wigmore PM, Mustafa S, El-Beltagy M, Lyons L, Umka J and Bennett G: Effects of 5-FU. Adv Exp Med Biol 678: 157-164, 2010.

20. Fuji K, Node M, Ito N, Fujita E, Takeda S and Unemi N: Terpenoids. L. antitumor-activity of diterpenoids from Rabdosia shikokiana var. occidentalis. Chem Pharm Bull 33: 1038-1042, 1985.

21. Takeda Y, Fujita T and Ueno A: Structures Of Leukamenins. Chem Lett 10: 1229-1232, 1981.

22. Ding L, Hou Q, Zhou Q, Zhang Q, Hou T and Liu G: Structure-activity relationships of eight ent-kaurene diterpenoids from three Isodon plants. Res Chem Intermed 36: 443-452, 2010.

23. Yang J, Liu Y, Xue C, Yu W, Zhang J and Qiao C: Synthesis and biological evaluation of glaucocalyxin A derivatives as potential anticancer agents. Eur J Med Chem 86: 235-241, 2014.
24. Morales A, Pérez P, Mendoza R, Compagnone R, Suarez AI, Arvelo F, Ramírez JL and Galindo-Castro I: Cytotoxic and proapoptotic activity of ent-16beta-17alpha-dihydroxykaurane on human mammary carcinoma cell line MCF-7. Cancer Lett 218: 109-116, 2005.

25. Geng S, Sun B, Lu R and Wang J: Coleusin factor, a novel anticancer diterpenoid, inhibits osteosarcoma growth by inducing bone morphogenetic protein-2-dependent differentiation. Mol Cancer Ther 13: 1431-1441, 2014.

26. Wang X: The expanding role of mitochondria in apoptosis. Genes Dev 15: 2922-2933, 2001.

27. Park MT and Lee SJ: Cell cycle and cancer. J Biochem Mol Biol 36: 60-65, 2003

28. Buolamwini JK: Cell cycle molecular targets in novel anticancer drug discovery. Curr Pharm Des 6: 379-392, 2000. 